\title{
Status analysis and countermeasures of Chinese community rehabilitation nursing based on professional talent cultivation theory
}

\author{
Sulan Long
}

\author{
Department of Nursing, Science and Technology College of Jiangxi University of Traditional Chinese \\ Medicine, Nanchang, 330004, China
}

Keywords: Status analysis on community rehabilitation nursing, Talent cultivation.

\begin{abstract}
There exist problems of late start, increasing demand, lagged community health service, uneven service level and lack of related professional talents in Chinese community nursing. This article proposes suitable countermeasures for community rehabilitation nursing suitable for Chinese practical situation such as strengthening training of rehabilitation specialty talents, and standardizing the rehabilitation nursing operation procedures, etc.
\end{abstract}

\section{Historical development of Chinese community rehabilitation}

After the Second World War, US proposed completed rehabilitation concept (Abbr. CBR). In 1976, WHO firstly proposed a new, effective and economical rehabilitation means, i.e. community rehabilitation, and suggested each member states especially the developing countries should actively carry out community rehabilitation, which is a good new for many developing countries and been carried out in China. This system mainly used the resources in this community to carry out rehabilitation and nursing service based on the existing conditions in the community aiming at service objects including chronic patients, the disabled, the aged, infants and children and pregnant and lying-in woman providing them with medical and sanitarian late-stage service so as to help them recover health and take care of themselves with confidence and go back to work and the society. It is convenient to carry out medical and prevention in communities with lower costs than hospital which can reduce the medical pressure of patients, hospitals and society so that it has developed in vigorously.

Chinese community rehabilitation started from 1986 and improved significantly in medical condition and level through thirty years' development. In short, Chinese community rehabilitation development can be divided into 4 stages: 1986 to 1990: the starting stage of Chinese community rehabilitation; 1991 to 1995: the pilot stage of Chinese community rehabilitation, 1996 to 2001: the all-round promotion stage, 2001 to now: the rapid development stage.

In 2002, Sixteenth CPC National Congress proposed "to build well-off society in an all-around way", and indicated that the disabled are the important components social community and rehabilitation is the precondition and basis for the work and life of handicapped people. Rehabilitation is the first demand and first requirement, and the main topic of DPF. Strive to fulfill the objective of "everyone enjoys rehabilitation service until the year of 2015". In the process of Chinese development, Chinese community rehabilitation career started from zero with each legal regulations issued, related teaching materials and colleges and universities started focusing and cultivating rehabilitation specialty talents. A series of rehabilitation teaching materials, and guiding books have been published in succession. The establishment of community rehabilitation training and service guiding expert team helped Chinese community rehabilitation develop into standardization and scientific. In the age of Internet, and new pattern, under the guidance of the government, related departments cooperated each other, social power support each other and the disabled and relatives 
actively participated in community rehabilitation as important components to play more and more critical part in future social development. Apply social method to help the disable get comprehensive rehabilitation service so as to realize of the objective of equal opportunity for all and full participation into social life. Community rehabilitation should go into communities, rural areas and provide service for families.

\section{The concept of community rehabilitation}

In 1981, WHO organized committee of experts to propose that community rehabilitation refers to "rehabilitation measurement taken in the community level and conducted by using and depending on community human resources including the damaged, disabled and handicapped people themselves, and their families and society". In China, community rehabilitation refers to a community rehabilitation system based on community's human resources with the guidance of community and engagement of health officers, civil officers, volunteers, associations and disabled persons, and their relieves to carry out general investigation, prevention and rehabilitation work among the community, so as to provide basic rehabilitation service for the disabled dispersed in the community and help them recover their functions to the utmost. In the organizational administration, incorporate community rehabilitation into community health service, and regional health planning and the unit annual working plan to implement objective management, formulate preferential politics, guarantee the disabled to gain rehabilitation service. Set up special rehabilitation technical guidance for the disabled, and training for rehabilitation technical backbones in basic level to prevent the confusion between social rehabilitation, social medical and social service.

\section{Analysis on the current situation of Chinese community rehabilitation nursing}

\section{Start late and development lagging behind}

The overall condition of Chinese community nursing is not good as being limited to Chinese practical condition, we started very late and moved forward in trials, learned while dong, and summarized the experience of failures for continuous progress and improvement. As community nursing rehabilitation is "imported goods". This community health service was carried out in Shanghai for the earliest time in the preliminary form of family ward, and then it developed gradually to the whole country. We can only follow the foreign methods step by step.

\section{Investigation on community rehabilitation resources}

We have made fishing expedition on the community rehabilitation resource and analysis are as follows. Human resources include doctors, teachers, FP staffs, volunteers, relieves, parents and grandparents of the disabled children, and students; material resources include rehabilitation equipment, barrier-free facilities, assistive devices; resources of knowledge environment include hospitals, rehabilitation organizations, special education schools, and kindergartens; conduct comprehensive nursing and rehabilitation training in community level to improve the patients' life quality. In recent years, with the growth in the living standard and worsening of aging and environmental pollution, emerging of food security, and increase of traffic violation and accidents, morbidity of chronic diseases such as high blood pressure, heart disease, cerebral infarction, and the quantity of hemiplegic patient have increase year by year. Most patients will choose the subsequent rehabilitation back to community after receiving treatment in hospitals, which can help them improve their own life quality to the upmost and recover the ability of living, studying and participating in social activities and finally go back to the society. The cost of community nursing is far lower than hospital and the patient satisfaction of community rehabilitation is higher. Community rehabilitation nursing plays a special role in disease treatment. Therefore, exploring the current situation and countermeasures of Chinese community rehabilitation nursing has great guiding significance for community to do rehabilitation nursing work and to further improve service quality. 


\section{The increasing demand for community rehabilitation nursing}

Since from opening and reform, Chinese economy has changed greatly. People's living standard in most areas have improved hugely with more rich materials, convenient logistics and higher incomes. People's concept is to keep healthy and long life so that they pay more attention to health care and well-being, which brought about the demand for community nursing. In the past, it is produced for the disabled and damaged living in community base to receive rehabilitation treatment and service locally, closely with lower costs and on time so as to solve their difficulties of "no way for rehabilitation". In recent years, "expensive to get medical treatment and to be hospitalized" brought great burden to the public and more and more people have urgent demand for nearby community health service to receive medical care.

\section{The level of community nursing staff is not unified}

The whole level of Chinese community nursing is low as it starts late. In the process of work, the experience of dealing with emergencies are not enough. In cities where medical level is higher, the nursing and rehabilitation level is high. But in remote and undeveloped areas and countryside, rehabilitation and nursing level are much backward even with no related service. The inherit concept is that community medical and nursing level is lower than hospital. In addition, the community work is hard, with low income and status, strong labor intensity and low income which has limited the activity of nursing staffs. In addition, the increasing tension between patients and doctors have prevented young people entering into the industry.

\section{Find solutions and countermeasures based on problems}

\section{Carry out community rehabilitation nursing education, and strengthen talent cultivation}

Under the new situation and new age, rehabilitation medical career has developed rapidly but professional talents in this major are in shortage. Research shows that China is now in urgent need of rehabilitation technical staffs for more than 3000 thousand people, which shows the importance and necessity of cultivating rehabilitation nurses. Take a medical science undergraduate in a Jiangxi college as the example, it sets up four-year undergraduate nursing major, Chinese-foreign cooperation nursing major, three-year specific nursing specialty, three-year specific medical cosmetic technology major. Now the college owns 1100 students, three subject teams including nursing foundation, clinical nursing, Chinese traditional medical nursing and a nursing lab training center. The college has insisted strengthening subject construction, improving teaching quality, and meanwhile actively expand subject characteristics, carry out teaching research and scientific research on nursing of traditional Chinese medicine, and nursing for the aged; pay attention to teaching team construction, and has formed the subject echelon and backbone teachers' team with subject leaders and academic leaders with teaching research and scientific research has been strengthened further.

\section{Adjust professional curriculum design and strengthen professional cooperation and exchange}

Rehabilitation nursing medical science is still a new subject in China in demand of new blood of subject leaders and subject construction. We can set course based on demands, and try to connect with practice as possible as we can in college professional course design. The community rehabilitation nursing major in Chinese colleges and universities are still not developed unable to meet the requirement of some special nursing. The demand for new type rehabilitation nursing talents has provided chances and background for Chinese higher medical colleges to set up community rehabilitation nursing courses. These make us lean more about foreign experience and catch up when cultivating professional technical talents. Take a college of medical science in Jiangxi as the example, the college has invited foreign nursing experts to make academic lectures while cultivating students and learning foreign experience, and meanwhile actively dispatched school teachers and students to attend international nursing academic meetings. Our school has cooperated to set up Chinese-foreign cooperative nursing major with Thomas University, Georgia, US, introduced American advanced 
nursing teaching concept and resources so as to cultivate high-level nursing talents to meet the international demands. Graduates from Sino-US cooperative class have been well received by employers.

\section{Pay attention to the practical procedure of rehabilitation specialty}

Regarding the educational reform, the college focuses on talent cultivation objective to carry out education and teaching reform, innovate talent cultivation mode, reform curriculum design system, and actively explore college-school cooperative schooling pattern. The colleges' internship bases and graduates' employment units spread into many "grade A class 3" hospitals in first and second tier cities. Regarding experimental training, the school's nursing experimental training covers the area of 1200 square meters equipped with basic nursing, critical disease nursing, nursing of traditional Chinese medicine, and other labs, equipped with advanced experimental apparatus such as multiple intelligent nursing anthropomorphic dummy, breathing machine, bedside monitor, defibrillator, etc. The total value of experimental apparatus and device is more than 5 million RMB. Students in the college carry forward the school motto of "learning and human oriented, stronger and specialized", receive the edification of occupational ideology of "moral composition, dedication, gratitude, caring", and achieved the preliminary nursing staff's humanistic glamour and professional skills through systematic theoretical and practical study.

\section{Standardize the workflow community rehabilitation}

In communities, it is necessary to set up rehabilitation coordinator, clear responsibility, institution and work records, and conduct rehabilitation demand research and set up archives, regularly organize and provide rehabilitation service and keep records, with working responsibility and system from community, village, rehabilitation center, equipped with rehabilitation equipment and knowledge popularization reading materials. Fill in and keep the "popularization demand registry form" and "Rehabilitation service record form" in "Disability popularization service archive", establish rehabilitation room, equip more than 1 rehabilitation staffs to provide rehabilitation service for the disabled, and carry out rehabilitation service training. Incorporate local community construction planning into county, city and regional level, formulate and carry out measurements and regularly hold meetings to develop the role of rehabilitation working office, set up rehabilitation technological guiding group, and standardize to use rehabilitation training files, popularize rehabilitation knowledge, and promote practical pragmatic training skills and multi-form rehabilitation service. Popularize rehabilitation knowledge and instruct training methods.

Community rehabilitation nursing should standardize workflow, as shown as below briefly:

\section{Strengthen and perfect community rehabilitation nursing service system}

Adjust and perfect existing service system, detailed measures are suggested as below: 1) personnel working on community rehabilitation nursing should own the certificate of professional medical worker authorized by governmental health administrative departments, and provide training and examination on basic theories, knowledge and skills, take up job through competition; 2) improve and increase the methods community nursing service to bring sunshine of care into each patient, hold knowledge lectures on health care, actively establish community information platform, invest primary and secondary equipment to rehabilitation center such as medical bicycle, wheelchair to satisfy the diversified demands of community citizens.

New chances and challenges are in front of us. Developing Chinses rehabilitation nursing are in the period of chance and challenge. We should continuously improve the service awareness and level of community nursing major and meanwhile know the latest leading edge application of basic subjects, application technology and modern science. Adhere to human oriented, conduct new type talent strategy, and strengthen teaching staff construction. Insist subject construction as the leader, professional construction as the foundation, increase subject and professional level, while standardizing professional setting, expanding major channels, and adjusting major level, strengthen the major connotation construction, perfect teaching procedures, and solidify primary education, 
stress practical skills, actively explore new channels of high-quality rehabilitation nursing talent cultivation, go toward to the whole country and the world based on Jiangxi, and own distinct advantages and characteristic among domestic similar colleges.

\section{Acknowledgement}

This article is the TCM science and technology planning project of 2016 Jiangxi Provincial Health and Family Planning Commission, "Empirical studies on Chinese medicine institution's' undergraduate talent training mode based on high quality nursing service concept" Project No. 2016 B029.

\section{Reference}

[1] Li Wei. Discussion on current development situation and countermeasure of Chinese community nursing, Medical Education, 2001, 10(5):11-13.

[2] Zhong Huasun. Current situation and development trend of Chinese community nursing, Nanfang Journal of Nursing, 2001, 8(5,6):1-2

[3] He Pingping. Economic growth, aging of population and increase of medical expenses, Financial Theory and Practice, 2006, 27(140):90-94.

[4] Tian Yongfeng. Current situation and thinking on Chinese community nursing, Journal of Shanxi Medical College for Continuing Education, 2002,12(1):4. 